\title{
CURSOS DE LETRAS: ALGUMAS REFLEXÕES SOBRE OS CRITÉRIOS DE AVALIAÇÃO DO MEC
}

\author{
Jocieli Aparecida de Oliveira PARDINHO. \\ Universidade Estadual do Paraná. ${ }^{1}$ \\ Dra. Alessandra Augusta Pereira da SILVA. \\ Universidade Estadual do Paraná. ${ }^{2}$
}

\begin{abstract}
RESUMO: Esta pesquisa tem como objeto de investigação a avaliação dos cursos de letras no Brasil a partir dos critérios estabelecidos pelo MEC para conceituar os cursos de graduação no país, confrontando-os com o conceito de emancipação humana advindas da teoria marxista, cuja perspectiva de formação humana engloba a superação da exploração do homem pelo homem. O objetivo geral é discutir os critérios de avaliação de cursos de letras com maior conceito pela MEC em relação à temática da formação de professores para a emancipação humana. A fundamentação teóricometodológica está subsidiada no materialismo histórico dialético a partir de literaturas que envolvem os estudos do Interacionismo Sociodiscursivo (BRONCKART, 1999/2003/2007/2009) e estudos marxistas (MARX, 2000; 2011). A pesquisa está dividida em quatro etapas, a saber i. Estudo da literatura; ii.) identificação dos critérios estabelecidos pelo MEC para a avaliação de cursos de letras no Brasil; iii) identificação de dois cursos com maior conceito obtido pelo MEC e; iv) analogia entre os critérios de maior peso avaliados nestes cursos pelo MEC em relação ao conceito de emancipação humana. Espera-se que tragamos, a partir dessa pesquisa, contribuições para a discussão sobre a avaliação de cursos de letras, ao mesmo tempo que a problematização dos critérios analisados seja realizada.
\end{abstract}

PALAVRAS-CHAVE: Curso de letras; materialismo histórico-dialético; Emancipação humana.

\begin{abstract}
This research has as object of investigation the evaluation of the Brazilian languages courses based on the criteria established by MEC to evaluate undergraduate courses in the country, confronting them with the concept of human emancipation resulting from Marxist theory, whose perspective of human formation encompasses the overcoming of man's exploitation by man. The general objective is to discuss the criteria of evaluation of courses of languages with the most concept by MEC involving the theme of teacher training for human emancipation. The theoreticalmethodological foundation is subsidized in historical-dialectical materialism from literatures that involves the studies of Sociodiscursive Interactionism (BRONCKART, 1999/2003/2007/2009) and Marxist studies (MARX, 2000; 2011). The research is divided into four stages, to know i) Study of the literature; ii.) Identification of the criteria established by MEC for the evaluation of courses of languages in Brazil; Iii) identification of two courses with greater concept obtained by MEC; iv) analogy between the criteria of greater weight evaluated in these courses by MEC in relation to the concept of human emancipation. We expected that, from this research, we will contribute to the discussion about the evaluation of languages courses, at the same time as the problematization of the analyzed criteria be done.
\end{abstract}

KEYWORDS: Course of languages; historical-dialectical materialism; human Emancipation.

\footnotetext{
${ }^{1}$ Programa de Iniciação Científica, bolsista da Fundação Araucária (2016/2017). Participante do grupo de pesquisa Linguagem, Desenvolvimento, Educação e suas Relações (CAPES).

2 Investigação vinculada ao projeto de pesquisa institucional intitulado Curso de letras: alguns critérios de avaliação da CAPES (pelo regime de trabalho da coautora - TIDE - tempo de dedicação exclusiva) e ao grupo de pesquisa Linguagem, Desenvolvimento, Educação e suas Relações (CAPES).
} 


\section{INTRODUÇÃO}

No presente artigo publicamos a investigação apresentada no Congresso LatinoAmericano de Formação de Professores de Línguas, ocorrido entre os dias vinte e cinco e vinte e seis de outubro de 2016, incluindo resultados parciais de um projeto de iniciação científica e de um projeto de pesquisa institucional da coautora do trabalho, ambos desenvolvidos na Universidade Estadual do Paraná. O estudo da literatura teve início em 2015 (pesquisa institucional) e a coleta de dados e continuidade do estudo da literatura foram iniciados no mês de fevereiro de 2016, e formalizados junto ao Núcleo de Pesquisa Interdisciplinar da referida instituição, em agosto de 2016, por isso a pesquisa possui resultados parciais.

O objetivo geral da pesquisa foi o de proporcionar a discussão dos critérios de avaliação do Ministério da Educação e Cultura (MEC), identificando os dois Cursos de letras Português e Inglês mais conceituados do Brasil, e confrontando-os com o conceito de emancipação humana, sob uma perspectiva pautada no materialismo histórico dialético, a partir de literaturas que envolvem os estudos do Interacionismo Sociodiscursivo (BRONCKART, 1999/2003/2007/2009) e de base marxistas (MARX, 2000/2011).

A presente pesquisa, justifica-se por destacar uma investigação de cursos de letras sob as lentes do materialismo histórico dialético, dentro dos aportes teórico- metodológicos do Interacionismo Sociodiscursivo (ISD) e especialmente pela teoria marxista de Dependência. Esse viés procura explicar o fenômeno, formação de professores, a partir da analogia realizada entre o conceito de emancipação humana e de critérios avaliativos desenvolvidos por uma instância governamental, o MEC, para "conceituar" os cursos de letras de 1 a 5, sendo o curso conceituado com o maior número aquele que atende todos os critérios desenvolvidos pelo MEC, portanto avaliado como um desempenho equivalente ao alto padrão internacional pelo órgão. Discutir como a avaliação de cursos de letras é caracterizada se justifica a partir da potencial contribuição trazido para discutir a qualidade desse curso para a formação docente, visando a uma emancipação humana, na perspectiva dessa pesquisa.

A coleta de dados foi realizada no site do Instituto Nacional de Estudos e Pesquisas Educacionais Anísio Teixeira (INEP), órgão criado pelo MEC. Nele foram pesquisados os dois cursos de letras mais conceituados de Brasil, os critérios de avaliação e o peso de cada um. Além da coleta, um estudo bibliográfico foi realizado a fim de selecionar os textos que foram os primeiros dados de análise para definir o conceito de emancipação humana.

O presente artigo está organizado em três partes, i. as discussões acerca das teorias que subsidiam a pesquisa, ii. a metodologia utilizada e iii. a análise dos resultados obtidos. Iniciamos com a fundamentação teórica, na sequência.

\section{FUNDAMENTAÇÃO TEÓRICA}

A fundamentação teórico-metodológica está ancorada no materialismo histórico dialético, em estudos marxistas e do ISD. Dessa forma, apresentamos, nesta seção, os princípios do materialismo histórico dialético dentro dos dois aportes teóricos de base da 
investigação, além de discutir o conceito de emancipação humana e os princípios metodológicos do ISD que foram adotados na pesquisa.

As teorias que embasam o materialismo histórico dialético, corroboram, portanto autores tais como Marx (1873/1968/1982/2011), Vigostki (1934/2009) e Bronckart (BRONCKART, 1999/2003/2007/2009). Para esses autores, o desenvolvimento do ser humano é resultado de uma longa e densa história em que processos, tanto filogenéticos quanto ontológicos se deram, permitindo a evolução de um animal primitivo ao que hoje se conhece como um ser social, o homem.

Partindo desse princípio, o ISD revela uma posição epistemológica, na qual são reconhecidas correntes da filosofia e das ciências humanas, aderindo a ideia de que as condutas humanas são providas em resultado de um processo histórico de socialização, sendo possibilitado por meio do desenvolvimento de ferramentas materiais e semióticas (MARX, 1873/1968/1982/2011; VIGOSTKI, 1934/2009).

Bronckart (BRONCKART, 1999/2003/2007/2009) afirma que as relações desenvolvidas pelos seres humanos entre si são resultados de uma longa e densa história, logo os processos se realizam por meio do agir humano, que sofreu uma longa e complexa evolução, a partir de sua origem filogenética. Assim, o trabalho, segundo Marx (1873/1968/1982/2011), apresenta a sua história ontogenética, a partir das diferentes relações que os homens constroem em diferentes momentos históricos. Portanto, as relações dos homens são como produtos históricos e, ao mesmo tempo, transitórios (MARX, 1873/1968/1982/2011). Dessa forma, tem-se um viés que converge três planos epistêmicos, o materialismo, o histórico e o dialético.

Materialista porque não existe uma visão monista do ser humano. Ao morrer, por exemplo, morre também sua alma. É histórico, pois, nessa perspectiva, só é possível compreender qualquer objeto da realidade a partir do conhecimento histórico dele. E é dialético porque a história não é linear, estática. No processo há avanços e há retrocessos, há, necessariamente o processo sincrético, mas também o sintético, permeando e impulsionando o desenvolvimento da humanidade.

Tendo posto isso, depreende-se que ao focar o desenvolvimento do ser humano, cada vez mais social, procura-se um nível de desenvolvimento cada vez mais elevado (VIGOSTKI, 1934/2009), implicando em uma possível emancipação humana. Ora, por que não estudar os cursos de formação de professores, neste caso, especificamente os cursos de letras, pensando em uma potencial formação para a emancipação humana.

Para se compreender a convergência que existe entre a emancipação ofertada na sociedade capitalista e o conceito de emancipação humana delimitada pelos estudiosos marxistas presentes no artigo, é necessário entender como funciona a base do capital, e de que maneira ocorre essa contradição.

Conforme Marx e Engels (2007), no sistema do Capital, há uma divisão de classes em "burguesia" e "proletariado", porém, o sistema aparentemente têm os indivíduos como sendo iguais. No entanto, isso ocorre somente no nível da lei, pois, na verdade os indivíduos são tratados de formas muito desiguais. Por essa negação das diferenças, segundo Mészáros (2008), não há a possibilidade, de nenhuma forma de emancipação no capital, pois a própria classe dos trabalhadores, gasta energia em lutas da emancipação da mulher, do negro, do homossexual, ao invés, de se juntarem unindo forças contra o capital.

Lessa (2012) afirma que os indivíduos que vivem na sociedade capitalista são impregnados da ideia de que seus atos têm importância na determinação dos seus "destinos". Portanto, na sociedade capitalista, cada indivíduo tem uma oportunidade ou obstáculo para 
acumular capital. O autor destaca, que, tanto o burguês quanto o operário, são resultados de um processo de alienação global, destacando o individualismo exacerbado sob a regência do capital.

A lógica da produção e reprodução do capital possui duas vertentes, de um lado está o proletariado, que está intimamente ligado a produção da matéria prima e do outro a burguesia que tem o poder absoluto no processo de produção, detentora da troca. Enquanto os proletários vendem sua força de trabalho para seus "chefes", garantindo assim o sustento de sua família, os detentores dos meios de produção usufruem do fruto dos trabalhos alheios (proletariado) e procuram ter cada vez mais valia. Segundo Lessa (2012, p.130), "o capital é uma criação dos homens, que passa a dominar a vida dos seus criadores", sendo assim, esse sistema escraviza os seus próprios criadores. Conforme o autor, a única maneira do término desse sistema que aliena e escraviza é a completa superação da exploração do homem pelo homem, sendo esse conceito, a base fundante da teoria utilizada neste artigo, a emancipação humana.

Lessa e Tonet (2012) destacam que para ocorrer, efetivamente, essa emancipação é necessário a completa erradicação do capital e de todas as suas categorias. Sem essa erradicação, é impossível a constituição de uma autêntica comunidade humana que não significa o aperfeiçoamento da cidadania, mas sim a sua mais completa superação. Em outras palavras,

A superação do capital e das alienações a ele associadas não significa o fim da História, mas sim a construção de uma formação social qualitativamente nova, em que as alienações serão, também, qualitativamente distintas daquelas que surgem e se desenvolvem num tecido social que tem a exploração do homem pelo homem como seu fundamento mais importante (Lessa, 2012, p.137).

$\mathrm{Na}$ "emancipação política" do capital, conforme Lessa e Tonet (2012) é que houve o início do exercício da cidadania, no qual o capitalista tem a propriedade do capital, e o proletariado vende sua força de trabalho. Contudo, perante o Estado, ambos são cidadãos, por isso são considerados "iguais", diante da lei, ignorando qualquer diferença entre os indivíduos, assim os autores reafirmam a teoria de Luckács que, por meio dessa "igualdade", o capitalista se torna possuidor de uma maior força para explorar os trabalhadores.

O Direito do trabalho em larga medida expressa estas necessidades de direitos e deveres na relação entre o capital e o assalariado. Aceitar tais direitos e deveres é condição indispensável para participar da reprodução dessa sociedade. Faz parte de tais direitos que os indivíduos tenham a possibilidade de lutarem para criar, ampliar e aperfeiçoar os seus direitos de cidadania, isto é, de que possam melhorar as condições de venda da força de trabalho ou, no caso de o cidadão ser um burguês, que possa melhorar as condições de compra da força de trabalho. O que significa, claro está, não questionar o próprio ato de compra e venda da força de trabalho, ou como diria Marx, não questionar, o "sistema de assalariamento" (Marx, 1977; 3778).

Ao pensar na reprodução do capital, em que a luta de classes é subjacente, bem como o trabalho assalariado, um outro elemento é fundamental, o Estado burguês (LESSA e TONET, 2012), além da "emancipação política". Por isso, cabe ao mercado determinar o que será produzido, como será e com quem ficará a riqueza produzida. Já em uma sociedade sem classes, o Estado burguês perderia sua razão de ser, no entanto, enquanto houver essa sociedade, ela estará, consequentemente, imbricada. 
Outro autor, Andrade (2012), corrobora os autores outrora apresentados. Para ele, o Estado está intimamente atrelado à reprodução do capital, sendo instrumento de dominação do trabalho pelo capital, sem as diferenças de classes trazidas pela sociedade capitalista, o Estado nem poderia existir. Dessa forma, no Estado, a única liberdade existente é a jurídica, e utiliza de sua força policial, judicial e econômica em prol do capital, no qual cada indivíduo é o único e responsável pelas condições em que se encontra. Segundo a notícia da página do BBC Brasil, o autor REUBEN (2016) afirma que menos de $1 \%$ da população é detentor das riquezas e os outros $99 \%$ são trabalhadores ou vivem na extrema pobreza.

Uma maneira de se lutar contra essa exploração é a greve que, de acordo com Lênin, ela seria uma "escola em que os operários apreendem a desfechar a guerra contra seus inimigos pela emancipação do todo o povo e os trabalhadores do jugo dos funcionários e do jugo do capital" (Lênin, 1979, p.42). Assim, é necessário observar que as greves e manifestações sociais dos trabalhadores não são apenas com o fim único o de melhorias salariais, mas tem como fim estratégico uma tomada da consciência do trabalhador para-si, ao fazer com que toda a classe trabalhadora se organize e lute contra os interesses da burguesia.

Para que essa consciência para-si venha a ocorrer, são necessários todos terem acesso a emancipação humana sendo essa a total superação da exploração do homem pelo homem, indo de encontro com a verdadeira liberdade que, para Lessa (2012), é correto reconhecer a liberdade como um fenômeno puramente social "fora do ser social não existe a liberdade", que atua apenas na relação entre teleologia e causalidade que caracteriza os atos humanos. Segundo Marx (2005) teremos, efetivamente, uma emancipação humana, quando o homem começar a perceber e organizar suas próprias forças.

\begin{abstract}
Somente quando o homem individual real reassimilar em si o cidadão abstrato, como homem individual, como ser genérico, em sua vida diária, em seu trabalho particular e em suas circunstâncias particulares, somente quando o homem tiver reconhecido e organizado suas forces propres (forças próprias), e consequentemente não mais separar o poder social de si mesmo na forma de poder político, somente então a emancipação humana será realizada. (Marx, 2005, p. 168)
\end{abstract}

Portanto, a única liberdade que encontramos no sistema atual é a liberdade jurídica que se distância de uma perspectiva emancipadora, não podendo ser confundidas entre si, pois a liberdade humana, segundo Tonet (2012), acontece como uma forma de sociabilidade, na qual os homens sejam realmente livres.

O conceito de emancipação humana permeou a análise e serviu para a reflexão dos resultados obtidos, pois se trata da completa superação da exploração do homem pelo homem. Sendo essa teoria a base reflexiva para um olhar crítico sobre os dados, pensando principalmente dessa formação de profissionais verdadeiramente emancipados que sejam capazes de enxergar as diversas problemáticas da formação para o exercício do magistério.

Após a explicitação do conceito de emancipação investigado na literatura, apresentamse a seguir, os princípios metodológicos de análise do ISD que subsidiou as análises realizadas.

Os princípios de análise do ISD parte de uma análise textual, constituída por dois níveis, o pré-textual e o textual. Segundo Silva (2015), o primeiro diz respeito à análise das condições de produção, incluindo os papéis sociais dos locutores e os objetivos da produção. $\mathrm{O}$ segundo remete à elaboração do plano textual global, elencando os seguimentos de orientação temática (SOT) ou conteúdos temáticos e seus desdobramentos, o qual Bronckart (1999/2003/2007/2009) intitula de seguimento de tratamento temático (STT). Os SOTS, 
podem ser identificados a partir de marcas linguísticas explicitas no texto são geralmente encontrados por sintagmas nominais, tais como: substantivos e pronomes.

O segundo nível de análise é o enunciativo, constituído pela análise de índice de pessoas, vozes e modalizações, observado a partir de escolhas linguísticas, advérbios e verbos principalmente, como as avaliações sobre os SOT são realizadas. Esse nível não será utilizado para este artigo. Ainda conforme a autora, os procedimentos de análise estão relacionados à proposta de uma leitura imanente, sendo originado do materialismo histórico dialético de Marx (1873/1968/1982/2011) e expandido por seus estudiosos contemporâneos.

\section{METODOLOGIA}

A pesquisa realizada é bibliográfica e de cunho quantitativo-qualitativo. Ela parte do estudo da literatura em um primeiro momento. Na sequência, estatísticas foram elaboradas a partir da identificação dos critérios estipulados pelo MEC para avaliação de cursos de Instituições de Ensino Superior, IEs e, finalmente, a análise torna-se qualitativa ao adotar-se os procedimentos metodológicos de análise do ISD, especificamente o SOT para que a última pergunta da pesquisa seja respondida. É importante salientar que a análise do contexto perpasse a análise quantitativa.

A investigação tem como locus a UNESPAR, campus de Campo Mourão e, teve início em 2015, como já mencionado, sendo atrelado formalmente ao PIBIC no mês de agosto de 2016. Além do estudo da literatura que a subsidia; a pesquisa é sequenciada pela identificação dos critérios estabelecidos pelo MEC para a avaliação de cursos de letras no Brasil; a identificação de dois cursos com maior conceito obtido pelo MEC e, por fim, a analogia entre os critérios de maior peso avaliados em relação a literatura explorada, etapa esta que se encontra a pesquisa atualmente, implicando em uma discussão parcial de seus resultados.

Para melhor entendimento do processo da pesquisa, inserimos, a seguir, nossas perguntas específicas da investigação, os instrumentos de coleta de dados e procedimentos de análise:

Quadro 1 - Perguntas da pesquisa, dados e procedimentos de análise

\begin{tabular}{|c|c|c|}
\hline Perguntas de Pesquisa & Dados & Procedimentos de análise \\
\hline $\begin{array}{l}\text { 1-Quais são os critérios estabelecidos pelo MEC } \\
\text { para avaliar cursos de letras? }\end{array}$ & $\begin{array}{lll}\text { Banco de dados do } & \\
\text { INEP. } & & \\
& & \\
\text { c }\end{array}$ & \begin{tabular}{|rr} 
Quantitativo & $\mathrm{e}$ \\
qualitativo: análise & do \\
contexto de produção
\end{tabular} \\
\hline $\begin{array}{l}\text { 2- Quais são os cursos de letras mais conceituados } \\
\text { no Brasil? }\end{array}$ & $\begin{array}{l}\text { Banco de dados do } \\
\text { INEP. }\end{array}$ & $\begin{array}{rr}\text { Quantitativo } & \mathrm{e} \\
\text { qualitativo: análise } & \mathrm{de} \\
\text { contexto de produção }\end{array}$ \\
\hline $\begin{array}{l}\text { 3- Qual é o peso de cada critério utilizado pelo } \\
\text { MEC na avaliação dos cursos do Brasil? }\end{array}$ & $\begin{array}{l}\text { Banco de dados do } \\
\text { INEP: }\end{array}$ & $\begin{array}{l}\text { (Quantitativo } \\
\text { qualitativo): análise textual } \\
\text { (SOT) }\end{array}$ \\
\hline $\begin{array}{l}\text { 4- Qual é a relação conceitual entre a literatura } \\
\text { explorada sobre formação de professores para uma } \\
\text { emancipação humana e os critérios avaliativos do } \\
\text { MEC? }\end{array}$ & & Qualitativo: SOT \\
\hline
\end{tabular}

Fonte: as autoras

O quadro acima apresenta as perguntas de pesquisa, os dados coletados e os procedimentos de análise utilizados. Os dados foram encontrados no banco de dados do INEP, 
cuja plataforma compunha planilha com a discriminação e a nota de cada Instituição de Ensino Superior. Com base nesses dados, foi possível localizar os dois cursos mais conceituados. E, por fim, houve um retorno à literatura estudada, cuja análise incidiu no nível de análise organizacional, delimitado na identificação do SOT "Emancipação Humana" e seu desdobramento a partir da identificação de seus STT. Essa identificação nos permitiu elaborar o conceito de Emancipação Humana para a nossa pesquisa e fazer uma analogia com os resultados de dados do INEP.

\section{RESULTADOS DE ANÁLISE}

A primeira e a segunda pergunta de pesquisa, quais os critérios de avaliação do MEC e quais os cursos mais conceituados por ele, levaram a investigar o contexto em que as avaliações são elaboradas. Já que esse órgão tem sob sua tutela a tarefa de avaliar os cursos de ensino superior do Brasil. Para tal, ele instituiu o INEP, sob a lei $\mathrm{n}^{\circ} 580$ do dia 13 de janeiro de 1937, que, inicialmente, se configurava como a primeira entidade a se estabelecer de maneira duradoura como fonte primária de documentação e investigação de atividades como o intercâmbio e assistência técnica pedagógica.

Em 1985, o INEP começou a ser uma ferramenta de assessoramento do MEC para a fomentação de pesquisa no Brasil, porém, no governo Collor (1990-1992) quase foi instinto, passando por várias mudanças. Nos anos 90, o Instituto atuou como um financiador de trabalhos acadêmicos voltados para a educação e, a partir de 1995, houve o processo de reestruturação do órgão. Com a reorganização do setor responsável pelos levantamentos estatísticos, pretendia-se que as informações educacionais pudessem, de fato, orientar a formulação de políticas do MEC. Dessa forma, nos últimos anos, o Instituto reorganizou o sistema de levantamentos estatísticos e teve como eixo central de atividades as avaliações em praticamente todos os níveis educacionais, incluindo o ensino superior, contexto desta pesquisa.

Ao acessar o INEP, foram identificados os dois cursos de letras na modalidade de licenciatura com as notas do Conceito Preliminar do Curso, CPC, mais altas: portuguêsespanhol da Universidade Federal do Ceará (UFC) e letras-português na Universidade Federal do Rio Grande do Sul (UFR). No entanto, devido à área de atuação das pesquisadoras envolvidas no projeto de pesquisa, utilizaram-se, como delimitação de corpora de análise, os dois Cursos de letras mais conceituados na licenciatura letras Português-Inglês, a saber, i. o curso de letras da Universidade Federal do Ceará, UFC, de Fortaleza/Ceará, cujo CPC foi totalizado em 3,9746 e; ii. o curso de letras da Universidade São Judas Tadeu, USJT, localizado em São Judas Tadeu/São Paulo, com o CPC 3,8162. Esses resultados são apresentados a seguir, no gráfico 1:

Gráfico 1 - CPC dos cursos mais conceituados 


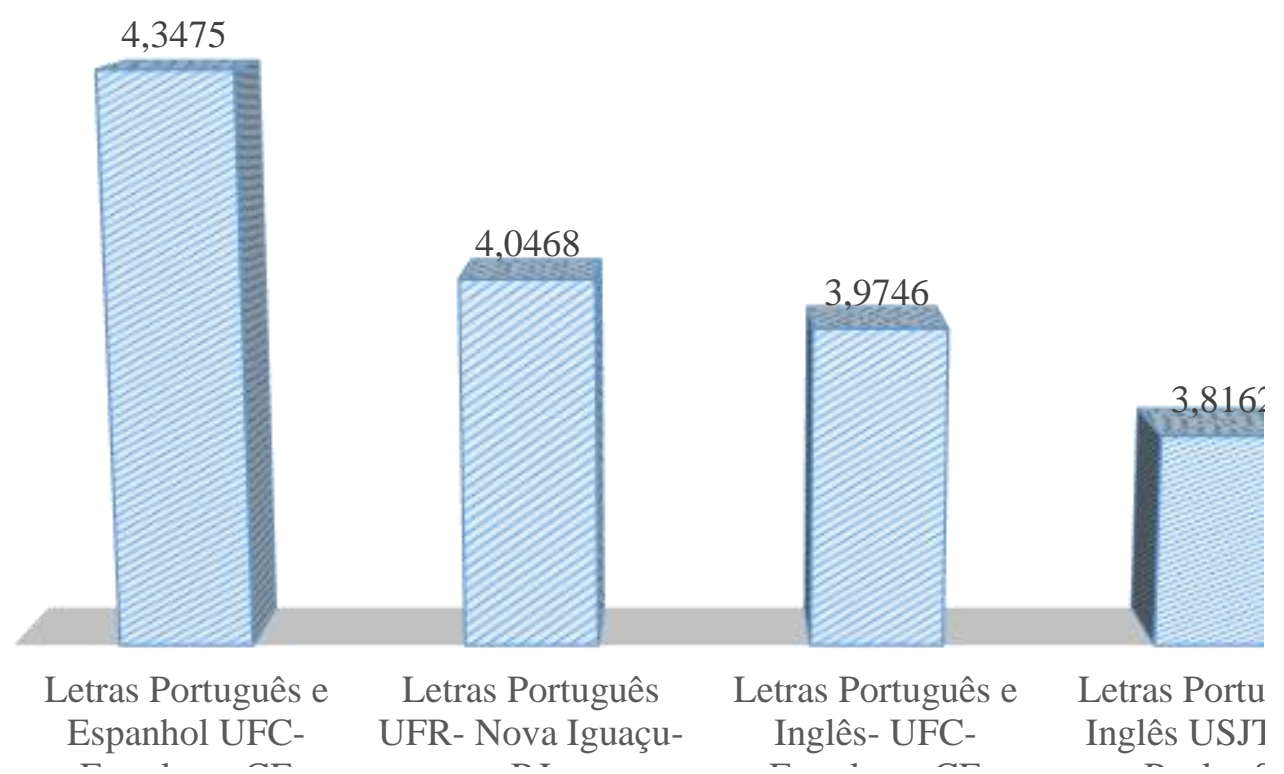

Fonte: as autoras

Ao analisar os dados apresentados no gráfico 1 que contém as notas e pesos na página do INEP, percebe-se que o curso de letras mais conceituado é da UFC, uma universidade pública e a segunda colocada, USJT, uma universidade privada, havendo uma pequena diferença entre os CPC. No entanto, ao analisar as notas, de acordo com o peso de cada critério, observou-se que, em alguns quesitos o curso mais conceituado no âmbito geral teve nota inferior à segunda. Isso ocorreu na avaliação da organização didático-pedagógica, da infraestrutura e instalações físicas, da oportunidade de ampliação e formação, dos concluintes participantes com nota do Exame Nacional do Ensino Médio (ENEM) e do número de docentes. Mesmo com essa diferença significativa, o curso de letras da UFC conseguiu ser a mais conceituada, pois possuiu nota mais alta no Exame Nacional dos Estudantes de Desempenho de Estudantes (ENADE), no número de matrículas e de doutores, no regime de trabalho, e um bom desempenho do Índice de Diferença de Desempenho (IDD).

Após a delimitação dos cursos de letras mais conceituados, procurou-se identificar quais critérios foram utilizados para a avaliação dos cursos. Ao dar início a esse processo, percebeu-se que a identificação deles poderia ser apresentada juntamente com seus pesos, respondendo, portanto, tanto as perguntas dois e três da pesquisa.

Os critérios elaborados pelo INEP são divididos em três grandes elementos, cada qual contendo um subconjunto de instrumentos avaliativos. Assim, tem-se $40 \%$ de peso para o ENADE, 30\% para o IDD, e 30\% para insumos.

O ENADE é o único elemento que é formado por um instrumento avaliativo, uma prova objetiva. O IDD é constituído por um formulário socioeconômico e a prova do ENADE. O primeiro é preenchido pelo aluno quando ele ingressa na graduação e, ao final do curso, a prova objetiva é realizada. A partir das duas aplicações, uma comparação entre eles é feita, dando origem ao IDD, indicando a diferença de desempenho entre o formulário preenchido pelo ingressante do curso e o resultado da avaliação do egresso no ENADE. Em relação ao critério Insumo, tem-se a seguinte divisão, avaliação do corpo docente, da infraestrutura e de recursos didático-pedagógicos. Dentro dos 30\% do Insumo, tem-se a seguinte divisão de pesos: $63 \%$ para o corpo docente, $10 \%$ para a infraestrutura e $27 \%$ para os recursos didáticos pedagógicos. 
No quesito corpo docente é levado em consideração o percentual de professores doutores, lotados no curso, e de professores que cumprem regime parcial ou integral (não horista) no curso. Na avaliação da infraestrutura e equipamentos são analisados as aulas práticas e o número de equipamentos disponíveis para o número de estudantes. Já em relação à avaliação de recursos didático-pedagógicos, contempla-se a análise de planos de ensino do curso (avaliação dos elementos do gênero, tais como, objetivos, procedimentos de ensino e avaliação, conteúdos e bibliografia da disciplina).

A título de ilustração, um gráfico contendo os critérios e os pesos em sua totalidade são apresentados a seguir:

Gráfico 2 - Peso de cada Critério

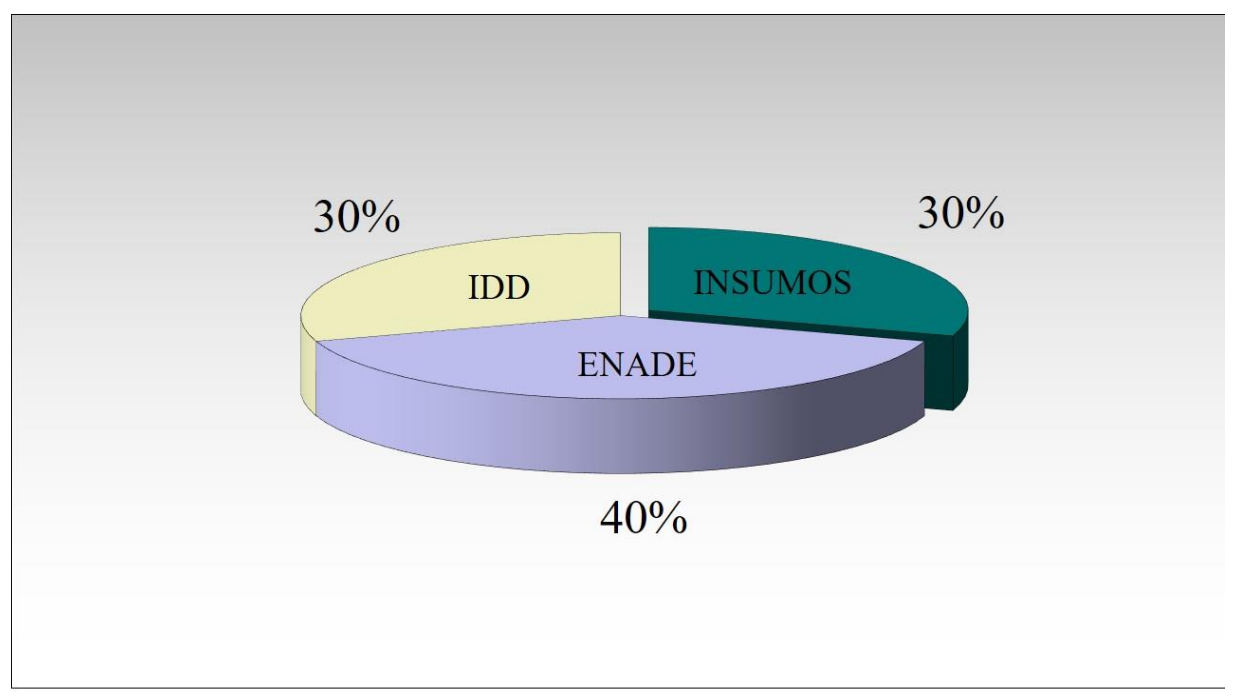

Fonte: as autoras

Como é apresentado no gráfico acima, o ENADE possui o peso de $40 \%$, já o IDD tem peso de $30 \%$ e, por fim, os Insumos que equivale a $30 \%$ está representado em uma escala 100\% dividido em: Corpo Docente 63\%, Infraestrutura 10\% e Recursos Didáticospedagógicos $27 \%$.

Em relação a esse resultado, se uma comparação de peso for realizada, é possível evidenciar que, de um total de $100 \%$ da avaliação dos cursos, somente $8 \%$ da totalidade dos valores distribuídos é atribuído aos recursos pedagógicos. Para compreender o que esses resultados estatísticos significam nesta pesquisa, apresentamos, na sequência, a análise do SOT Emancipação Humana.

Para responder a última pergunta da pesquisa, Qual é a relação conceitual entre a literatura explorada sobre formação de professores para uma emancipação humana e os critérios avaliativos do MEC, realizou-se a análise de SOT e STT de três capítulos de livros escritos por contemporâneos de Marx, que utilizam de uma linguagem mais simples para explicar o que foi dito pelo autor. Por se tratar de uma pesquisa de resultados parciais, nesse momento, esses autores foram delimitados. Porém, na continuidade da pesquisa, será feita também a análise de referências bibliográficas cunhados por Marx.

Ao realizar a análise do capítulo Emancipação Política, Democracia e Cidadania (LESSA, TONET, 2012), formado por 5 laudas e 22 parágrafos, foram identificados 28 SOTS 
e apenas 1 se tratava da temática selecionada que é a emancipação humana. Nesse SOT, foram localizados 2 STTS.

O capítulo Formação da Consciência de Classe Em-si e Para-si (NETO, 2012), constituído de 19 laudas e 64 parágrafos, possui 87 SOTS. Dentre eles, 14 SOTS sobre emancipação humana, incluindo 23 STTS.

Já no capítulo O Fenômeno da Alienação de (LESSA, 2012), 27 laudas e 89 parágrafos, destacam-se 145 SOTS, sendo 4 SOTS sobre emancipação humana e 5 STTS.

O quadro 3 sintetiza os resultados outrora demonstrado:

Quadro 2 - Síntese do SOT Emancipação Humana na literatura Investigada.

\begin{tabular}{|c|c|c|c|c|}
\hline Título do texto & \multicolumn{2}{|c|}{ Parágrafo } & STT & $\begin{array}{l}\text { Número de } \\
\text { ocorrências }\end{array}$ \\
\hline \multirow{2}{*}{$\begin{array}{c}\text { Emancipação } \\
\text { política, } \\
\text { democracia e } \\
\text { cidadania. }\end{array}$} & \multirow{2}{*}{\multicolumn{2}{|c|}{$10^{\circ}$}} & Reino da liberdade humana & 01 \\
\hline & & & $\begin{array}{l}\text { Superação da sociedade de classes pela extinção } \\
\text { do capital }\end{array}$ & 01 \\
\hline \multirow{10}{*}{$\begin{array}{l}\text { Formação da } \\
\text { consciência de } \\
\text { classe em-si e } \\
\text { para-si. }\end{array}$} & $1^{\circ}$ & $21^{\circ}$ & \multirow{5}{*}{$\begin{array}{l}\text { Superação da sociedade de classes pela extinção } \\
\text { do capital }\end{array}$} & \multirow[t]{5}{*}{13} \\
\hline & $3^{\circ}$ & $33^{\circ}$ & & \\
\hline & $38^{\circ}$ & $41^{\circ}$ & & \\
\hline & $44^{\circ}$ & \multirow[t]{2}{*}{$45^{\circ}$} & & \\
\hline & $54^{\circ}$ & & & \\
\hline & $1^{\circ}$ & $20^{\circ}$ & \multirow{5}{*}{$\begin{array}{l}\text { Desenvolvimento da consciência de classe para-si } \\
\text { do proletariado }\end{array}$} & \multirow[t]{5}{*}{10} \\
\hline & $24^{\circ}$ & $31^{\circ}$ & & \\
\hline & $33^{\circ}$ & $34^{\circ}$ & & \\
\hline & $40^{\circ}$ & $43^{\circ}$ & & \\
\hline & $54^{\circ}$ & & & \\
\hline \multirow[t]{3}{*}{$\begin{array}{l}\text { O Fenômeno da } \\
\text { Alienação. }\end{array}$} & $15^{\circ}$ & $31^{\circ}$ & $\begin{array}{l}\text { Superação da sociedade de classes pela extinção } \\
\text { do capital }\end{array}$ & 03 \\
\hline & \multicolumn{2}{|l|}{$50^{\circ}$} & $\begin{array}{l}\text { Desenvolvimento da consciência de classe para-si } \\
\text { do proletariado }\end{array}$ & 01 \\
\hline & \multicolumn{2}{|l|}{$68^{\circ}$} & Reino da Liberdade humana. & 01 \\
\hline \multicolumn{4}{|l|}{ TOTAL DE STT } & 30 \\
\hline
\end{tabular}

Fonte: as autoras

Nos capítulos dos livros analisados, conforme quadro acima, foram identificados 30 STTS sobre o SOT Emancipação Humana. Dentre eles, 17 STT remetem ao Capital, 11 STT correspondem à consciência humana a partir de um desenvolvimento do ser social em-si para para-si e 2 STT visam a vertente do significado de liberdade humana e. É importante ressaltar que mais de um STT foi recorrente em um mesmo parágrafo. Dessa forma, o número de STT é muito maior que o número de parágrafos, como pode ser observado nas colunas $2 \mathrm{e} 4$. Além disso, o mesmo STT, por vezes, foi identificado em mais de um texto, como é o caso do STT superação da sociedade de classes pela extinção do capital do que aparece em todos os textos. 
Dado que o STT nada mais é do que o desenvolvimento do tema dentro do texto, intitulado por Bronckart (2009) como subtema, foi possível observar as mesmas marcas linguísticas que evidenciaram o SOT para sua identificação, ou seja, os sintagmas nominais. Para exemplificar tal fenômeno, um excerto analisado é apresentado na sequência.

Excerto do capítulo Formação da consciência de classe em-si e para-si (Neto,2012).

[...]_A formação da consciência de classe em-si e para-si comparecem como uma determinação reflexiva, em que a consciência para-si somente pode constituir-se através da consciência em-si, quer dizer, embora o trabalho assalariado venha ao mundo como uma determinação objetiva do capital, a perspectiva do trabalho pode transpor as determinações impostas pelo capital e apontar para uma perspectiva de superação tanto das estruturas que determinam a existência do trabalho como trabalhado abstrato quanto da organização social da humanidade na forma de sociedade de classes. (Neto, 2012, p. 81).

Como pode ser observado pelas marcas linguísticas destacadas em negrito, dois STT foram elencados no excerto acima. O primeiro inicia-se na linha primeira linha e termina na terceira linha, introduzido pelo sintagma nominal "A". O segundo STT começa na linha quatro e suas marcas linguísticas encontradas são o pronome "do", e na mesma linha comparece novamente o pronome "pelo", há também substantivos que pode-se destacar "determinações" na mesma linha, na quinta "superação", e por fim na sexta linha "organização". Essas marcas linguísticas foram destacadas em todos os capítulos analisados para que, tanto a identificação do SOT emancipação humana fosse realizada, quanto a dos STT correspondente a ele.

Tendo posto isso, apresentamos o desenvolvimento de cada STT evidenciados nos textos, pela ordem de recorrência em ordem decrescente, iniciando-se pelo STT capital.

De acordo com Neto (2012), o Capital é um modo de produção social cuja propriedade privada implica em uma centralização de riquezas infindável, do desenvolvimento da tecnologia, da produção e do consumo. Essa centralidade é condicionada à exploração do homem pelo próprio homem, como princípio fundante. Para uma perspectiva emancipadora, é necessária a superação dessa organização social da humanidade na forma de sociedade de classes. Por isso, ao ser visto pela vertente da emancipação humana, o Capital precisa ser extinto e todas as classes sociais que o personificam. As lutas de classes sociais, segundo Lessa (2012), acontecem no interior do Capital, no qual o proletariado é o único possibilitador da libertação de si e de toda humanidade em relação ao Capital, pois para uma verdadeira emancipação é necessária a completa superação da exploração do homem pelo homem. Em outras palavras, todas as estruturas que determinam a existência desse modo de produção precisam ser superadas, incluindo o trabalho abstrato.

O STT "Desenvolvimento da consciência para-si do proletariado" engloba a mudança de um indivíduo que passa do nível do individualismo para um que se reconhece como um sujeito de classes, superando, portanto, a consciência em-si, possibilitando uma verdadeira emancipação humana. Por isso, Marx (1873/1968/1982/2011) vislumbrava formas de conduzir uma constituição do proletariado para além do desenvolvimento da consciência política, enfatizando a necessidade de condições objetivas para que houvesse ruptura com os determinantes estruturais do Capital. Em outras palavras, seria necessário que a sociedade conseguisse produzir riqueza suficiente para todos para que uma revolução fosse possível. Essa revolução depende de um indivíduo com uma consciência de classe.

O último STT, "Reino da liberdade" trata da diferença entre a emancipação política, ou seja, de uma liberdade meramente jurídica, em que "todos são iguais perante a lei" dentro 
da democracia ditada no Capital e a emancipação humana que caracteriza o que Lessa e Tonet (2012) intitulam de reino da liberdade. Nesse reino, o ser humano tem o trabalho tão somente como valor de uso, diferentemente do trabalho abstrato, tido como valor de troca, ou em palavras triviais, como uma moeda de troca.

Em síntese, o conceito de emancipação humana, analisado na literatura dessa investigação, refere-se a superação da sociedade de classes pela extinção do capital, ao desenvolvimento da consciência de classe para-si e ao reino da liberdade humana. É esse conceito que será considerado para refletir sobre a analogia realizada com os resultados de avaliação do MEC.

Se voltarmos para os elementos que constituem a avaliação do MEC, a saber, o ENADE, o IDD e o Insumo é possível observar o quanto são dependentes de condições objetivas que advém do Estado ou, em outras palavras, dependem do orçamento disponibilizado pelo Estado, via governos, para se efetivarem. Há, portanto, uma contradição entre a avaliação realizada, por se tratar consideravelmente de questões orçamentárias, e o próprio proponente da avaliação, o Estado, que é responsável por gerir as condições objetivas dos cursos.

Ao mesmo tempo, sabe-se que a avaliação dos cursos tem um papel protagonista na sua existência já que o Estado pode cortar recursos, ampliá-los ou ainda extinguir o curso dependendo de seu resultado na avaliação. Ora, se o Estado é responsável por prover as condições necessárias para um determinado curso existir no ensino superior, como Ele poderia ter o poder de transferir, de certa forma, sua responsabilidade às IEs, por meio dessa avaliação? Nesse ponto é que a contradição fica explícita.

A avaliação é necessária, no entender, das autoras deste artigo. No entanto, os critérios e pesos de avaliação realizados pelo MEC, via INEP, enfatizam, predominantemente as condições objetivas, demandando recursos financeiros que, muitas vezes, são recusados pelo próprio MEC, entidade representativa do Estado.

Por último, mas não menos importante, a analogia permitiu, ao analisar o conceito de emancipação humana a partir da base marxista, observar que para que ela se efetive, há a necessidade de um modelo de sociedade que priorize a "superação da exploração do homem pelo homem", no qual todas as pessoas tenham condições dignas de viver em uma verdadeira sociedade igualitária, em que os indivíduos coletivamente governem suas vidas, havendo, portanto, a extinção do Estado burguês.

Em outras palavras, não há emancipação humana na presença do Estado burguês.

Dessa forma, esses critérios se tornam contraditórios, pois, de diversas maneiras, é avaliado aquilo que não está no alcance do aluno, do professor e da instituição, pois a maioria dos elementos avaliados de forma negativa ou com mau desempenho é de responsabilidade do Estado. A avaliação se torna falha ao avaliar o que deve ser melhorado por uma instância maior, inclusive a que a financia, mascarando com dados a realidade que só quem conhece uma perspectiva emancipadora pode enxergar.

Nesse caso, as políticas públicas educacionais deveriam ser revistas para suprir as necessidades das instituições, tanto nas condições subjetivas como nas objetivas, como, por exemplo, investindo na infraestrutura, na formação profissional, em matérias didáticos, entre outras necessidades que são, muitas vezes, ignoradas. 
Hypolito (1999), afirma que o exercício do magistério está sendo cada vez mais exigida a partir de cursos de ensino superior em contraste com um processo de desqualificação e enfraquecimento, devido o enxugamento dos cursos de formação, com a redução de carga horária do curso ou, muitas vezes, ofertadas à distância, sem a infraestrutura adequada para uma boa formação. Outro fator são as condições inaceitáveis do trabalho docente intervindo radicalmente tanto na formação como nos aprimoramentos da profissionalização, contendo aspectos subjetivos e objetivos que constroem e são desenvolvidos no processo de trabalho excepcionalmente na formação inicial e práticas docentes.

Por isso, a urgência de se discutir, por meio de dados qualitativos e quantitativos, sobre a formação de professores emancipados, que segundo Netto (2011), se torna necessária a investigação da essência do trabalho do professor formador ${ }^{3}$ no modo de produção capitalista brasileiro ocupa um lugar de destaque, mesmo tendo consciência de que "no domínio científico, toda conclusão é provisória, sujeita à comprovação, retificação, abandono" (NETTO, 2011, p. 26).

Ao formar profissionais que visem a emancipação humana, se forma seres críticos, pensantes, que realmente se preocupam com a situação da educação brasileira, consequentemente, será formado um professor comprometido com a formação de alunos com uma visão de mundo ampla, de opinião formada sobre as diversas questões políticas e sociais atuais. Outro fator, são as condições inaceitáveis do trabalho docente intervindo radicalmente tanto na formação como nos aprimoramentos da profissionalização, contendo aspectos subjetivos e objetivos que constroem e são desenvolvidos no processo de trabalho excepcionalmente na formação inicial e práticas docentes. Por isso, a necessidade de serem repensadas as matrizes curriculares dos cursos, priorizando a formação voltada a emancipação humana.

\section{CONSIDERAÇÕES FINAIS}

Conclui-se, por meio de resultados parciais da pesquisa realizada, pois tem-se a necessidade de uma maior compreensão do conceito de emancipação humana para ser apresentado uma analogia mais aprofundada, sendo esta a nossa pretensão para o ano de 2017. Portanto, até o momento, percebe-se a necessidade de serem consideradas adequadamente as condições subjetivas e objetivas que são imbricadas. Assim é visível a urgência de ocorrerem mudanças nas políticas públicas em termos de educação, proporcionando investimentos na formação dos profissionais da educação. A contribuição trazida, por meio da pesquisa é a identificação e análise dos critérios de maior peso pelo MEC para avaliação dos cursos de letras, com o intuito de uma abertura da discussão dos modelos sociais preestabelecidos, validados e legitimados para um curso que pretende formar um professor para a emancipação humana. Propiciando, também uma discussão que traga contribuições para a readequação de matrizes curriculares que vise a formação de professores não somente para o atendimento do mercado do trabalho, mas para a formação de pessoas que possam realmente ter acesso a uma emancipação humana. Enfim, vale ressaltar que os dados encontrados apontam para as lacunas existentes nos critérios de avaliação do MEC, demonstrando a relevância de cada critério e a importância de serem repensados.

\footnotetext{
${ }^{3}$ A essência do trabalho do professor nesta pesquisa é tomada como o fator que mais determina a formação docente, por isso ela está diretamente atrelada à discussão da formação de professores para a emancipação humana.
} 


\section{REFERÊNCIAS}

Livro:

BRONCKART, J. P. Atividade de linguagem, textos e discursos: Por um interacionismo sócio-discursivo. Trad. Anna Rachel Machado, Péricles Cunha. São Paulo: EDUC, 1999//2003/2007/2009.

MARX, K. O Capital: crítica da economia política: livro I. Ed. 28. Tradução de SANT’ANNA, R. Rio de Janeiro: Civilização Brasileira, 1873/1968/1982/2011.

. Salário, preço e lucro. Texto 3. São Paulo: Sociais, 1977.

MARX, K.; ENGELS, F. Manifesto do partido comunista. Tradução de Álvaro Pina. São Paulo: Boitempo, 2007.

MÉSZÁROS, I. Filosofia, ideologia e ciência social. Trad. Ester Vaisman. São Paulo: Boitempo,2008.

NETTO, J. P. Introdução ao Estudo do Método de Marx. São Paulo: Expressão Popular, $2011 / 2012$.

VYGOTSKY, L. S. 1934. A construção do pensamento e da linguagem. Tradução de Paulo Bezerra. São Paulo: Editora Martins Fontes, 2009.

\section{Capítulo de Livro:}

ANDRADE, M.A. De Marx a Mészáros: A inseparável relação entre o Estado e a Reprodução do Capital. In: MELO. E.; PANIAGO. M.C.S; ANDRADE. M.A. (Org.) Marx, Mészáros e o Estado. São Paulo: Instituto Lukács, 2012.

HYPOLITO, A. M. Trabalho docente e profissionalização: sonho prometido ou sonho negado? In: ; VEIGA, I. P; CUNHA, M. I. da (Org.) Desmistificando a

Profissionalização do Magistério. Campinas, SP: Papirus, 1999.

LÊNIN, V.I. Sobre as greves. In: LÊNIN, V.I. Sobre os sindicatos. São Paulo: Polis, 1979.

LESSA, S. Fenômeno da Alienação In: LESSA, S. Para compreender a ontologia de Luckács. Unijuií: Coleção Filosofia, 2012, p.123-150.

LESSA, S.; TONET, I. Emancipação política, democracia e cidadania. In: LESSA, S; TONET. I. Proletariado e sujeito revolucionário. São Paulo: Instituto Lukács, 2012, p. 4550 .

NETO. A.B.S. Formação da Consciência de Classe Em-si e Para-si. In: BERTOLO. E.; MOREIRA. L.A.L; JIMENEZ. S. (Org.). Trabalho educação e formação humana frente a necessidade histórica da revolução São Paulo: Instituto Luckács, 2012. p.81-100.

Dissertação/ teses: 
SILVA, Alessandra Augusta Pereira da. O trabalho do professor formador de língua inglesa e a natureza de aprendizagem na formação em pré serviço.2015. $299 \mathrm{f}$. Tese (Doutorado em Estudos da Linguagem), UEL- Universidade Estadual de Londrina, Londrina, 2015.

\section{Textos on-line:}

INEP. Instituto Nacional de Estudos e Pesquisas Educacionais Anísio Teixeira, 2016. Disponível em: 〈http://portal.inep.gov.br/educacao-superior/indicadores/cpc >. Acessado em: 19 jul.2016.

REUBEN. A. BBC Brasil, 2016. Disponível em: <http://www.bbc.com/portuguese/noticias/2016/01/160118_riqueza_estudo_oxfam_fn>. Acessado em: 18 jul.2016.

\section{Apêndice}

Quadro 2 - Síntese do SOT Emancipação Humana na literatura Investigada.

\begin{tabular}{|c|c|c|c|}
\hline Título do texto & Parágrafo & STT & $\begin{array}{l}\text { Número de } \\
\text { ocorrências }\end{array}$ \\
\hline \multirow{2}{*}{$\begin{array}{ll}\text { Capítulo } & \text { V- } \\
\text { Emancipação } & \\
\text { política, } & \\
\text { democracia } & \mathrm{e} \\
\text { cidadania. } & \end{array}$} & \multirow[t]{2}{*}{$10^{\circ}$} & Reino da liberdade humana & 01 \\
\hline & & $\begin{array}{l}\text { Superação da sociedade de classes pela } \\
\text { extinção do capital }\end{array}$ & 01 \\
\hline \multirow{7}{*}{$\begin{array}{lr}\text { Formação } & \text { da } \\
\text { consciência } & \text { de } \\
\text { classe em-si } & \text { e } \\
\text { para-si. } & \end{array}$} & \multirow[t]{2}{*}{$1^{\circ}$} & $\begin{array}{l}\text { Desenvolvimento da consciência de classe } \\
\text { para-si do proletariado }\end{array}$ & 01 \\
\hline & & $\begin{array}{l}\text { Superação da sociedade de classes pela } \\
\text { extinção do capital }\end{array}$ & 02 \\
\hline & $20^{\circ}$ & $\begin{array}{l}\text { Desenvolvimento da consciência de classe } \\
\text { para-si do proletariado }\end{array}$ & 01 \\
\hline & $21^{\circ}$ & $\begin{array}{l}\text { Superação da sociedade de classes pela } \\
\text { extinção do capital }\end{array}$ & 01 \\
\hline & $24^{\circ}$ & $\begin{array}{l}\text { Desenvolvimento da consciência de classe } \\
\text { para-si do proletariado }\end{array}$ & 01 \\
\hline & \multirow[t]{2}{*}{$31^{\circ}$} & $\begin{array}{l}\text { Desenvolvimento da consciência de classe } \\
\text { para-si do proletariado }\end{array}$ & 02 \\
\hline & & $\begin{array}{l}\text { Superação da sociedade de classes pela } \\
\text { extinção do capital }\end{array}$ & 02 \\
\hline
\end{tabular}




\begin{tabular}{|c|c|c|c|}
\hline & $33^{\circ}$ & $\begin{array}{l}\text { Desenvolvimento da consciência de classe } \\
\text { para-si do proletariado }\end{array}$ & 01 \\
\hline & & $\begin{array}{l}\text { Superação da sociedade de classes pela } \\
\text { extinção do capital }\end{array}$ & 02 \\
\hline & $34^{\circ}$ & $\begin{array}{l}\text { Desenvolvimento da consciência de classe } \\
\text { para-si do proletariado }\end{array}$ & 01 \\
\hline & $38^{\circ}$ & $\begin{array}{l}\text { Superação da sociedade de classes pela } \\
\text { extinção do capital }\end{array}$ & 01 \\
\hline & $40^{\circ}$ & $\begin{array}{l}\text { Desenvolvimento da consciência de classe } \\
\text { para-si do proletariado }\end{array}$ & 01 \\
\hline & $41^{\circ}$ & $\begin{array}{l}\text { Superação da sociedade de classes pela } \\
\text { extinção do capital }\end{array}$ & 01 \\
\hline & $43^{\circ}$ & $\begin{array}{l}\text { Desenvolvimento da consciência de classe } \\
\text { para-si do proletariado }\end{array}$ & 01 \\
\hline & $44^{\circ}$ & $\begin{array}{l}\text { Superação da sociedade de classes pela } \\
\text { extinção do capital }\end{array}$ & 01 \\
\hline & $45^{\circ}$ & $\begin{array}{l}\text { Superação da sociedade de classes pela } \\
\text { extinção do capital }\end{array}$ & 02 \\
\hline & $54^{\circ}$ & $\begin{array}{l}\text { Desenvolvimento da consciência de classe } \\
\text { para-si do proletariado }\end{array}$ & 01 \\
\hline & & $\begin{array}{l}\text { Superação da sociedade de classes pela } \\
\text { extinção do capital }\end{array}$ & 01 \\
\hline $\begin{array}{l}\text { O Fenômeno da } \\
\text { Alienação. }\end{array}$ & $15^{\circ}$ & $\begin{array}{l}\text { Superação da sociedade de classes pela } \\
\text { extinção do capital }\end{array}$ & 01 \\
\hline & $31^{\circ}$ & $\begin{array}{l}\text { Superação da sociedade de classes pela } \\
\text { extinção do capital }\end{array}$ & 02 \\
\hline & $50^{\circ}$ & $\begin{array}{l}\text { Desenvolvimento da consciência de classe } \\
\text { para-si do proletariado }\end{array}$ & 01 \\
\hline & $68^{\circ}$ & Reino da Liberdade humana. & 01 \\
\hline TOTAL D & & & 30 \\
\hline
\end{tabular}

Fonte: as autoras 